\title{
Educación de campo y educación multiana: reflexiones y desafíos en una escuela transamazónica
}

\author{
Ronaldo Henrique Santana \\ ronaldobio@ufpa.br \\ https://orcid.org/0000-0002-8006-1289 \\ Universidade Federal do Pará (UFPA). Doutor em Estudos de Cultura Contemporânea \\ (UFMT). Professor Adjunto da Faculdade de Etnodiversidade - UFPA-Campus \\ Universitário de Altamira \\ Altamira - PA, Brasil. \\ Suziane Pereira de Freitas \\ suzianepereira97@gmail.com \\ https://orcid.org/0000-0002-0775-9824 \\ Universidade Federal do Pará (UFPA). Licenciada em Educação do Campo (UFPA). \\ Pacajá - PA, Brasil. \\ Marcos Marques Formigosa \\ mformigosa@ufpa.br \\ https://orcid.org/0000-0001-6279-1459
}

Universidade Federal do Pará (UFPA) Doutor em Ensino (UNIVATES). Professor Adjunto da Faculdade de Etnodiversidade - UFPA - Campus Universitário de Altamira Altamira - PA, Brasil.

Recibido: 31/março/2021 Aceptado: 01/Setembro/2021

\begin{abstract}
Resumen
A partir de los aspectos teóricos y prácticos involucrados en la concepción de la Educación Rural y en la relación que se establece en la práctica pedagógica dentro del aula y en los procesos de enseñanza-aprendizaje en una clase plurianual, el presente trabajo tiene como objetivo discutir los desafíos del trabajo docente en la implementación del plan de estudios escolar en el contexto de una escuela de campo, denominada EMEF N. Sr ${ }^{\mathrm{a}}$. dos Remedios, ubicado en una calle que cruza la BR-230, en el municipio de Pacajá, Estado de Pará. El principal punto a abordar son los complejos procesos históricos que culminaron con la propuesta de una Educación Rural que se opone a la idea caricaturizada de una educación rural, atrasada y meramente reproductiva. A partir de una búsqueda bibliográfica y entrevistas semiestructuradas con profesores de escuela, presentaremos las discusiones sobre las dificultades que señalan dichos profesionales en el ejercicio de su trabajo con una clase multicolor y el territorio en el que se inserta la escuela, en el complejidades de la transamazônica.
\end{abstract}

Palabras clave: Educación rural; Escuela de campo; Clases multianuales.

\section{Educação do campo e ensino multiano: reflexões e desafios numa escola da transamazônica}

\section{Resumo}

Baseado nos aspectos teóricos e práticos envolvidos na concepção de Educação do Campo e na relação que se estabelece na prática pedagógica dentro da sala de aula e nos processos do ensinar-aprender em uma turma multiano, este artigo visa discutir os desafios do trabalho 
docente na implementação do currículo escolar no contexto de uma escola do campo, denominada E.M.E.F. N. Sra ${ }^{\mathrm{a}}$ dos Remédios, situada numa vicinal que cruza a BR-230, no município de Pacajá, Estado do Pará. O ponto principal a ser tratado são os complexos processos históricos que culminaram com a proposta de uma Educação do Campo que contrapõe a caricaturizada ideia de uma educação rural, retrógrada e meramente reprodutivista. A partir de uma pesquisa bibliográfica e a realização de entrevistas semiestruturadas com professores da escola, apresentaremos as discussões acerca das dificuldades elencadas por tais profissionais no exercício de seu trabalho com uma turma multiano e o território em que a escola se insere, nos meandros da transamazônica..

Palavras chave: Educação do Campo; Escola do campo; Classes multi ano.

\title{
FIELD EDUCATION AND MULTIAN TEACHING: REFLECTIONS AND CHALLENGES IN A TRANSAMAZON SCHOOL
}

\begin{abstract}
Based on the theoretical and practical aspects involved in the conception of Rural Education and in the relationship established in the pedagogical practice within the classroom and in the teaching-learning processes in a multiannual class, the present work aims to discuss the challenges of work teacher in the implementation of the school curriculum in the context of a country school, called EMEF N. Sr ${ }^{\mathrm{a}}$. dos Remédios, located in a street that crosses the BR230, in the municipality of Pacajá, State of Pará. The main point to be dealt with is the complex historical processes that culminated in the proposal of a Rural Education that opposes the caricatured idea of a rural, backward and merely reproductive education. Based on a bibliographic research and the performance of semi-structured interviews with school teachers, we will present the discussions about the difficulties listed by such professionals in the exercise of their work with a multiannual class and the territory in which the school is inserted, in the intricacies of the transamazônica.
\end{abstract}

Keywords: Rural Education; Countryside school; Multian classes.

\section{INTRODUÇÃO}

Esta pesquisa visa discorrer sobre a implementação do currículo e os desafios do trabalho docente em uma turma multiano ${ }^{1}\left(8^{\circ}\right.$ e $\left.9^{\circ}\right)$ ano, da Escola Municipal de Ensino Fundamental Nossa Senhora dos Remédios (E.M.E.F. Nª Sr ${ }^{\mathrm{a}}$. dos Remédio), localizada na Vicinal $^{2}$ Ladeira da Velha - BR 230, Rodovia Transamazônica, município de Pacajá, situado ao Sudoeste do Estado do Pará. Como sabemos, são inúmeros os desafios enfrentados pelos

\footnotetext{
${ }^{1} \mathrm{Na}$ literatura é comum encontrarmos a expressão multisseriada, considerando que antes da Lei n ${ }^{\mathrm{o}} 11.274 / 2006$ a organização se dava por série e não por ano e tal expressão ainda é comumente utilizada. Neste texto, faremos uso da expressão multino.

2 Denomina-se "vicinal" a estrada, o caminho, o trajeto, as incontáveis ruas que cortam a Rodovia Transamazônica e dão sentido à existência de diferentes povoados e comunidades camponesas, servem de rotas de deslocamento entre as casas e o centro da cidade.
} 
docentes no exercício de sua profissão, sobretudo quando pensamos nas realidades daqueles que atuam em escolas do campo ${ }^{3}$ distribuídas ao longo de vicinais que cruzam essa rodovia.

Essas escolas absorvem a heterogeneidade da população campesina da Amazônia Brasileira: agricultores familiares, extrativistas, pescadores artesanais, ribeirinhos, assentados e acampados da reforma agrária, trabalhadores assalariados rurais, quilombolas, caiçaras, povos da floresta, caboclos e outros que produzam suas condições materiais de existência a partir do trabalho no meio rural, conforme aponta Hage (2010, p. 351):

A Amazônia apresenta uma estrutura peculiar, com elevado grau de complexidade, muito diferente de outras regiões do país, uma vez que convivem em um mesmo espaço, de forma contraditória e conflitual, economias extrativistas tradicionais, com processos de trabalho de tecnologias simples, e atividades industriais e grandes empreendimentos que usam modernas tecnologias .

É em cenários como estes, onde essas escolas estão inseridas, que Caldart et al. (2012) sinalizam que a Educação do Campo só pode ser compreendida como um fenômeno da realidade brasileira a partir do seu contexto histórico de origem, sua temporalidade e sua práxis. A ideia de pensar uma Educação que seja efetivamente do Campo já remete a um processo complexo, dinâmico, não apreensivo, de territórios, temporalidades, histórias de vida, fluxos e confluências identitárias, de expressões e/ou contradições dos sujeitos que ali habitam, de vivências e significações únicas trazidas pelos estudantes, convergidas na interculturalidade da sala de aula, mediada na relação com o docente e seu fazer pedagógico. A Educação do Campo, enquanto campo epistemológico contra hegemônico, combate a lógica do ensino homogeneizante, verticalizado, com currículos engessados e descolados da realidade, tal qual aquelas apresentadas pelo currículo tradicional (LIMA; MELO, 2016), com vistas a um enquadramento profissional estéril, fruto da reprodução do capital e sua lógica de funcionamento importado do modelo de escola urbana.

As escolas do campo situadas nesse contexto apresentam características ou situações comuns a de outras escolas de distintas regiões do Brasil, mas de forma agravada: fragilidade ou ausência de estrutura escolar adequada, carência de materiais didáticos, professores com baixos salários, incerteza de permanência de vínculo, carga horária inadequada, insuficiência ou ausência de formação continuada ou sequer formação inicial compatível com as matérias ministradas, escolas sem Projeto Político Pedagógico (PPP), ou quando possuem estão desatualizados ou são "emprestados" de outra unidade, problemas de acesso às escolas pela

\footnotetext{
${ }^{3}$ De acordo com o decreto 7.352/2010, em seu Art. 1, considera-se escola do campo "aquela situada em área rural, conforme definida pela Fundação Instituto Brasileiro de Geografia e Estatística - IBGE, ou aquela situada em área urbana, desde que atenda predominantemente a população do campo" (BRASIL, 2010).
} 
distância ou precariedade das vicinais ${ }^{4}$, inexistência ou sucateamento do transporte escolar, escassez de recursos financeiros, prevalência da unidocência ou multiano, dentre outros (HAGE, 2010; 2011; TENÓRIO et al., 2019; SANTOS et al., 2020). Além disso, Libâneo (2012, p. 22) pontua que “[...] são reiteradas as demandas pela ampliação dos recursos financeiros para todos os níveis e modalidades de ensino. Há um volume considerável de investigações sobre a situação dos salários e das condições de trabalho e formação dos professores $[\ldots] "$.

Não cabe aqui desdobrar todos os problemas apontados, mas assinalar as dificuldades desta região do País e demonstrar as estratégias utilizadas pelos professores para uma educação de qualidade. Paulo Freire (1996), ao afirmar que estudar é um ato revolucionário nos leva a pensar que superar tais reptos requer perseverança e resiliência dos sujeitos envolvidos no ato educativo. Por este prisma, o próprio conceito de Educação do Campo já remete a um processo de enfrentamento. Para Caldart (2008, p. 69), esta modalidade de educação "[...] tem raiz na sua materialidade de origem e no movimento histórico da realidade a que se refere", na força coletiva e na luta por políticas públicas e defesa dos "territórios imateriais", face às tensões e disputas pela implementação dos direitos das comunidades camponesas.

Frente a estas problemáticas, o trabalho do professor precisa estar centrado na escola, na comunidade, em um planejamento curricular que inclua os sujeitos envolvidos e o que os cerca. Desta forma, o presente trabalho visa discutir os desafios do trabalho docente na implementação do currículo escolar no contexto de uma turma multiano, como estratégia para desnudar a realidade enfrentada por estes profissionais que lidam com as problemáticas supracitadas.

Por se tratar de turma multiano, pensamos nas diversas situações apontadas por Hage (2010), no acesso e permanência à uma educação de qualidade que seja ofertada pelo Estado, bem como as estratégias metodológicas empregadas no enfrentamento do fracasso escolar, que afeta especialmente esta parcela da população brasileira.

\begin{abstract}
As situações que vivenciam os sujeitos do campo para garantir o acesso e a qualidade da educação nas escolas multisseriadas, em grande medida estão diretamente relacionadas com a política educacional e curricular das escolas do campo na Amazônia, situação que envolve fortes repercussões sobre o fracasso escolar dos sujeitos do campo, expresso nas taxas elevadas de distorção idadesérie, de reprovação e de dificuldades de aprendizagem da leitura e escrita,
\end{abstract}

\footnotetext{
${ }^{4}$ A dificuldade é agravada no período de inverno. Regionalmente, a Amazônia é conhecida por possuir apenas duas Estações no ano: Inverno (período chuvoso) e verão (estiagem).
} 
comprometendo a qualidade do processo educacional ofertado por essas escolas. (HAGE, 2010, p. 352).

Além desses apontamentos iniciais, recorreremos às contribuições de Caldart (2008), Caldart e Molina (2004), Libâneo (2012), Santos (2015), Gadotti (2000), Arroyo, Caldart e Molina (2004), Hage (2010; 2011), Santos e Moura (2010), Tenório et al. (2019), Santos et al. (2020) dentre outros, que tratam da temática do estudo.

Ao considerar os múltiplos desafios apontados para o exercício profissional docente nas escolas do campo da transamazônica, elencamos neste ensaio, aqueles recorrentes nas falas das docentes participantes do estudo, responsáveis por ministrar todo o bloco de disciplinas. Além das questões relativas à precariedade da escola, a falta de estrutura adequada e ausência de materiais didáticos, são emergentes questões como as dificuldades e exigências para implementação do ensino multiano, a sobreposição de funções dos professores e a verticalização do currículo.

Os dados que compõem esta análise foram obtidos a partir das vivências decorrentes dos Tempos Comunidades (TC) 5 e dos Estágios Supervisionados do curso de Licenciatura em Educação do Campo, em uma escola próxima a comunidade onde uma das autoras viveu. Nessa escola, a mesma se alfabetizou e estudou até o $7^{\circ}$ ano (antiga $6^{\mathrm{a}}$ série), por ser a escola mais próxima de sua residência.

Deste modo, os dados foram produzidos em pesquisas de campo no período de 2014 a 2019 e compuseram os relatórios ${ }^{6}$ dos TC's, assim como os dos Estágios Supervisionados I, além de observações in loco, entrevistas semiestruturadas ${ }^{7}$ realizadas com duas professoras que atuam em turmas multiano dos anos finais do Ensino Fundamental. Esses dados foram gravados em mídias, com registros foto e fonográficos, bem como no diário de campo e posteriormente analisados, pelo prisma da análise qualitativa de conteúdo, que segundo Leite (2008) busca interpretar toda e qualquer mensagem em si, contida no objeto, bem como as características e nuances vinculadas a ela.

\footnotetext{
${ }^{5}$ Tempo Comunidade é o período em que os alunos do Curso de Licenciatura em Educação do Campo da Universidade Federal do Pará retornam para suas comunidades de pertença e são estimulados a realizarem pesquisas nessas comunidades, a partir das dimensões culturais, econômicas, sociais, educacionais, ambientais, etc., sob orientação de um docente do curso, bem como encaminhamentos dados no decorrer do Tempo Universidade (TU), quando os alunos estão inseridos no contexto da universidade, logo, o curso funciona em regime de alternância entre esses dois tempos formativos, considerados indissociáveis nesse processo.

${ }^{6}$ A cada alternância os estudantes devem entregar um relatório de Tempo Comunidade consubstanciado em dados referentes à pesquisa que engloba elementos atinentes ao contexto da comunidade e da escola.

${ }^{7}$ As entrevistas foram realizadas presencialmente, antes do período da pandemia de COVID-19, em etapas de pesquisa de campo que se intensificaram em 2018 e 2019, mas que se iniciaram a partir de 2014.
} 
Para tanto, além desta introdução, o artigo está dividido em três seções: A primeira discorre sobre os pressupostos históricos e epistemológicos da Educação do Campo e do ensino multiano enquanto estratégia metodológica para as escolas do campo. $\mathrm{Na}$ segunda, elencamos as características da escola N. Sra ${ }^{\mathrm{a}}$. dos Remédios e da comunidade onde foi realizado o estudo; na terceira, tratamos das estratégias utilizadas pelas professoras na implementação do currículo e seus desafios na efetivação em uma turma multiano do Sistema de Organização Modular de Ensino (SOME), adotado pelo município de Pacajá para escolas situadas em regiões rurais e, por fim, as considerações finais.

\title{
1. EDUCAÇÃO DO CAMPO, HISTÓRIA E ENFRENTAMENTOS
}

Como salientamos anteriormente, a Educação do Campo surge nas constantes lutas por direitos e igualdade de acesso à Educação, não só de qualidade, mas personalizada e satisfatória aos moradores do meio rural. A política nacional de Educação do Campo surgiu das lutas dos movimentos sociais do campo, visado a partir da construção de ideias, objetivos e expectativas de trabalhadores e trabalhadoras do campo, daí a escola do campo passou a ser pensada como espaço de reflexão, tendo em vista a realidade e sua particularidade dos povos do campo.

\begin{abstract}
A educação do campo, tratada como educação rural na legislação brasileira, tem um significado que incorpora os espaços da floresta, da pecuária, das minas e da agricultura, mas os ultrapassa ao acolher em si os espaços pesqueiro, caiçaras, ribeirinhos e extrativistas. $\mathrm{O}$ campo nesse sentido, mais do que um perímetro não urbano, é um campo de possibilidades que dinamizam a ligação dos seres humanos com a própria produção das condições da existência social e com as realizações da sociedade humana. (ARROYO; CALDART; MOLINA, 2004, p. 176).
\end{abstract}

Para Vendramini (2007, p. 123), a Educação do Campo não é fruto de políticas públicas advindas de boas intenções do Estado, mas “[...] emerge de um movimento social, da mobilização dos trabalhadores do campo e da luta social. É fruto da organização coletiva dos trabalhadores diante do desemprego, da precarização do trabalho e da ausência de condições materiais de sobrevivência para todos".

O processo de reconhecimento para uma Educação "do", "no" e "com" o Campo surge na superação da ideia de "rural" como espaço de retrocesso, atraso e abandono, face ao urbano. O termo "campo", aplicado à educação nasce nos espaços de discussões promovidas pelos movimentos sociais e demais instituições ${ }^{8}$ que buscavam uma educação que levasse

\footnotetext{
${ }^{8}$ Vilhena Junior e Mourão (2012) apontam que tais discussões nascem no I Encontro Nacional de Educadores da Reforma Agrária (I ENERA), realizado em 1997, das quais participaram instituições como a Organização das Nações Unidas para a Educação, a Ciência e Cultura - Unesco, Movimento dos Sem Terra - MST,
} 
em conta as especificidades do meio rural e a dinâmica da produção humana do trabalho, bem como uma escola que não fosse tipo diferente de escola, mas que considera os sujeitos do campo como "sujeitos sociais, que também podem ajudar no processo de humanização do conjunto da sociedade, com suas lutas, suas histórias, seu trabalho, seus saberes, sua cultura, seu jeito." (CALDART, 2011). Assim, pensou-se uma educação paradoxalmente utópica, mas tangível, verdadeiramente destinada aos sujeitos do campo, que contrapunha a perspectiva de uma educação não só "para” o campo, mas “com” o campo.

Embora a Educação do Campo tenha avançado em alguns aspectos ao longo da história da educação brasileira, dentro das perspectivas do ensino rural, dado seu caráter projetista de um espaço retrógrado, o campo foi tratado, do ponto de vista formal, como extensão da cidade, de modo a não dialogar com os sujeitos do campo, seu território e identidades (ARROYO; CALDART; MOLINA, 2004). Ainda segundo os autores, além de negar o direito à educação de qualidade, negava-se o direito à incorporação dos elementos constituintes da cultura e das condições de existências dentro desses modos de vida.

A Educação do Campo, por sua vez, se alinha como a identificação dos saberes com a terra, o território imaterial, na compreensão das relações entre o meio ambiente e os processos de produção humana, na proposição e incorporação de outras formas de produzir, como a economia solidária, projetos escolares-comunitários, nos modos de ser, sentir e viver o campo, no estímulo à memória coletiva, nas formas de compartilhar, no diálogo com os diferentes saberes e culturas, dentre outros, para o fomento de sociedades sustentáveis em contraponto a uma ideia de desenvolvimento sustentável.

\begin{abstract}
A Educação do Campo, que tem sido tratada como educação rural na legislação brasileira, tem um significado que incorpora os espaços da floresta, da pecuária, das minas e da agricultura, mas os ultrapassa ao acolher em si os espaços pesqueiros, caiçaras, ribeirinhos e extrativistas. O campo, nesse sentido, mais do que um perímetro não urbano, é um campo de possibilidades que dinamizam a ligação dos seres humanos com a própria produção das condições da existência social e com as realizações da sociedade humana (ARROYO; CALDART; MOLINA, 2004, p. 176).
\end{abstract}

São esses apontamentos empreendidos nas lutas protagonizadas pelos movimentos sociais, que desencadeou em alguns marcos legais, como o Decreto 7.352/2010, que traz, dentre outras coisas, a necessidade de implementação de políticas públicas que superem os direitos, historicamente negados dos sujeitos do campo, conforme se observa no seu Art. $3^{\text {o: }}$.

Universidade de Brasília - UNB, o Fundo das Nações Unidas para a Infância (UNICEF), a Conferência Nacional dos Bispos do Brasil - CNBB, dentre outras. 
Caberá à União criar e implementar mecanismos que garantam a manutenção e o desenvolvimento da educação do campo nas políticas públicas educacionais, com o objetivo de superar as defasagens históricas de acesso à educação escolar pelas populações do campo, visando em especial: I - reduzir os indicadores de analfabetismo com a oferta de políticas de educação de jovens e adultos, nas localidades onde vivem e trabalham, respeitando suas especificidades quanto aos horários e calendário escolar [...] (BRASIL, 2010, s/p, arquivo digital).

Assim, é legítimo a tentativa por parte dos movimentos sociais e instituições parceiras o objetivo de reivindicar e redefinir profundamente uma Educação do Campo, na superação e recuperação dos atrasos educacionais, na implementação de políticas compensatórias que equacionem tais desigualdades, combatam a estereotipação dos sujeitos do campo, que reorientem o currículo, as metodologias e calendários, conforme preconiza o Art. 28 da Lei de Diretrizes e Bases (9.394/96). Tais ações superariam as relegadas marcas deixadas pelo modelo de educação rural implementado historicamente, pois ela:

[...] por motivos socioculturais, sempre foi relegada a planos inferiores, e teve por retaguarda ideológica o elitismo acentuado do processo educacional, aqui instalado pelos jesuítas e a interpretação político-ideológica da oligarquia agrária conhecida popularmente na expressão: "gente da roça não carece de estudos. Isso é coisa de gente da cidade” (LEITE, 1999, p. 14).

As escolas rurais no Brasil foram construídas sem o apoio necessário pelo Estado e tardiamente para poder se desenvolver. Nos textos constitucionais até 1891, as escolas rurais sequer foram citadas (BRASIL, 2002). Depois de treze anos a Constituição de 1946 houveram debates em torno da democratização sobre a educação da escola básica. No dia 20 de dezembro de 1961 foi divulgada a Lei 4.024, a primeira Lei de Diretrizes e Bases da Educação Nacional - LDB, gerando expectativas na organização e universalização da Educação brasileira. No entanto, pouco se avançou nas particularidades dos povos do campo. Cabe dizer, como salienta Brito (2020, p. 92), que apenas a construção de escolas no campo não garante o acesso a um ensino de qualidade e, muitas vezes, as mesmas são alienadas a adotarem um único modelo de ensino “[...] que não fazem sentido para os sujeitos envolvidos, oferecendo práticas fragmentadas que não contribuem para a formação integral do indivíduo" (BRITO, 2020, p. 92). Essa lei buscou alternativas para a espacialização das escolas públicas no meio rural, mas não houve preocupação com as distinções do campo brasileiro.

[...] a educação do campo tem se caracterizado como um espaço de precariedade por descasos, especialmente pela ausência de políticas públicas para as populações que lá residem. Essa situação tem repercutido nesta realidade social, na ausência de estradas apropriadas para escoamento da produção; na falta de atendimento adequado à saúde; na falta de assistência técnica; no não acesso à educação básica e superior de qualidade, entre outros (PINHEIRO, 2007, p. 88). 
Começaram então a buscar ações para que houvesse articulação entre teoria e prática, construindo coletivamente o conhecimento, a valorização dos saberes, as trocas de experiências. Além disso, lutaram pelo direito à terra, à saúde e à educação, procurando organizar também suas produções que são resultados do trabalho humano, assim, construindo e implementando ações com vista às melhorias de vida dos sujeitos envolvidos.

Somente na década de 90, com a nova LDB (Lei n ${ }^{\circ}$ 9.394/96), e intensas reivindicações e lutas dos movimentos sociais em prol das populações do campo é que, finalmente, as políticas públicas educacionais começaram a ser formuladas e implementadas, normatizando a educação a ser desenvolvida no meio rural.

O dispositivo legal que trata da disponibilização de Educação Básica para as populações do campo é encontrado no artigo 28 da Lei n. 9394/96 (Lei de Diretrizes e Bases da Educação Nacional). Essa conquista se deu a partir da organização dos movimentos sociais. [...] Como marco dessa luta, tem-se o Programa Nacional de Educação na Reforma (Pronera), implantado em 1998 (VILHENA JUNIOR; MOURÃO, 2010, p. 177).

A partir daí, a Educação do Campo passa a ser garantida em lei, mesmo com os obstáculos de efetivação de ações reais na sociedade, numa educação que faça sentido e dialogue com as famílias do campo, numa perspectiva de educação popular e cidadã, sem fins meramente extensionista de um currículo urbano.

No entanto, ainda encontramos no cenário amazônico escolas que acumulam problemas herdados da educação rural. Além disso, há outras em que suas turmas se organizam em formato multiano, onde concentram-se alunos de diferentes idades e séries/anos, prevalecendo nos anos iniciais do Ensino Fundamental. Entretanto, nas comunidades campesinas da região da Transamazônica, têm surgido turmas multianos nos anos finais do Ensino Fundamental, como é o caso das turmas encontradas da E. M. E. F. N. $\mathrm{Sr}^{\mathrm{a}}$. dos Remédios, conforme veremos a seguir.

\section{SOBRE A E. M. E. F. N. Sra . DOS REMÉDIOS}

Como apontado na introdução deste texto a E. M. E. F. N. Sra . dos Remédios, lócus desta pesquisa, está localizada na Vicinal Ladeira da Velha a $10 \mathrm{~km}$ da BR 230, Rodovia Transamazônica, município de Pacajá (PA), conforme se observa na Figura 1 abaixo. 
Figura 1: Localização do Município de Pacajá - PA.

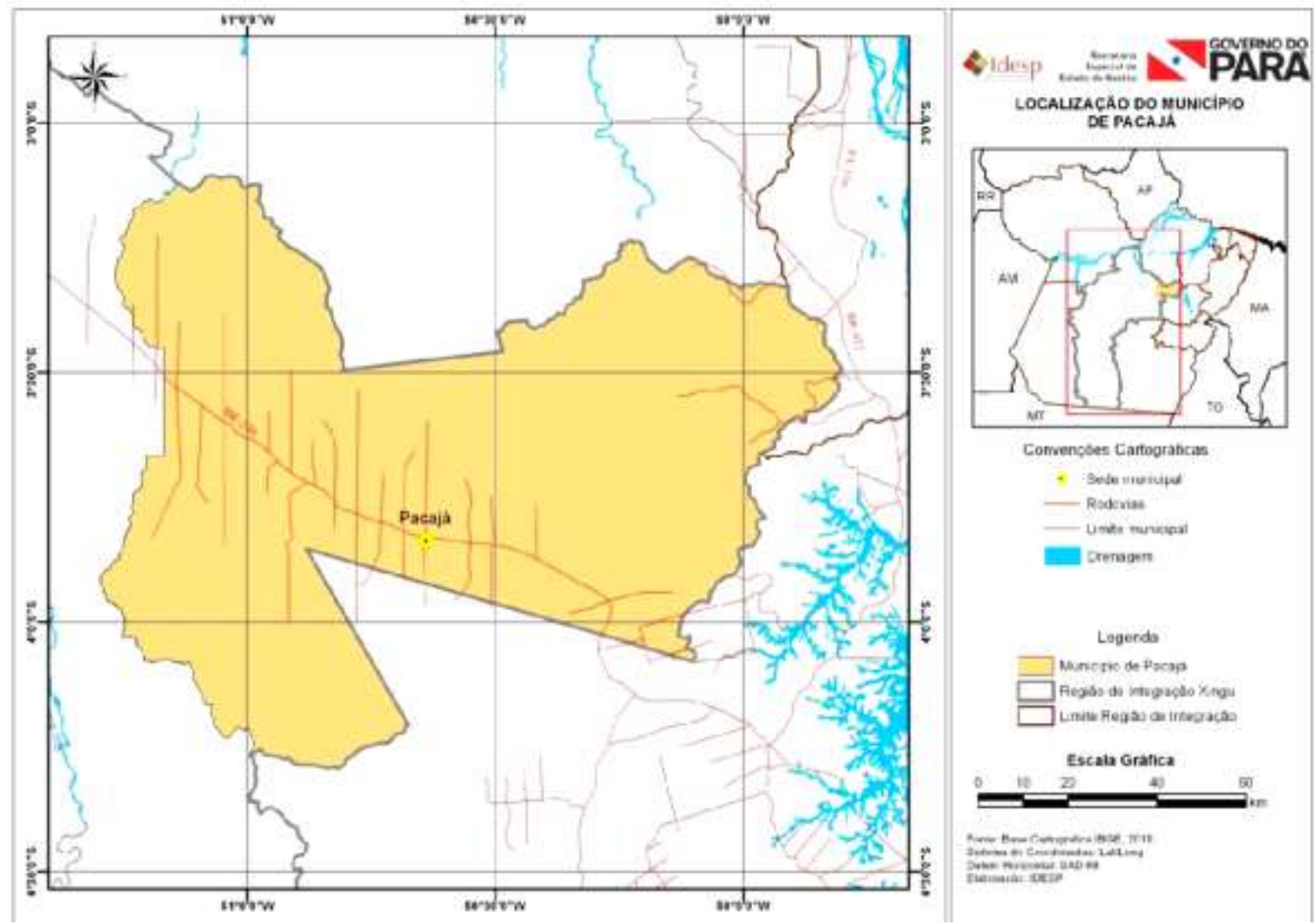

Fonte: IBGE/SEI. Elaboração: IDESP, 2017.

A escola foi criada no ano de 1985, pelos moradores do local, recebeu o nome de Remédios em homenagem à primeira professora que se chamava Maria dos Remédios. Como em muitas comunidades campesinas, a escola foi criada sem lugar fixo para as aulas, e chegou a funcionar em igrejas, barracões e nas casas dos próprios moradores. No ano de 1990, foi doado por um morador recém-chegado na comunidade um pedaço de terra com dimensão de 30x60m, mas apenas em 1995, ela foi construída pela prefeitura, com área de $154 \mathrm{~m}^{2}$

\begin{abstract}
A escola fica bem próxima da casa da professora Terezinha, na Ladeira da Velha, de ocupação mais antiga (anos 1970). O modelo é de loteamentos retangulares de 100 hectares - o padrão do INCRA para os chamados colonos. A escola ocupa um pedaço de terreno cedido pela própria Terezinha e seu esposo, Carlos. É possível observar duas salas, uma para o fundamental menor e outra para o maior, na qual trabalha outra professora (PANTOJA, 2018, p. 188).
\end{abstract}

Ela é construída aos moldes das escolas do campo para a região: de madeira, coberta com telha de barro e pintada à tinta. Possui três salas de aulas, porém só duas estão em uso no momento, a outra encontra-se com a estrutura comprometida prestes a desabar, o que compromete não só a segurança dos estudantes, bem como evidencia a ausência de qualquer conforto. A professora sinaliza que a questão da estrutura, está entre os principais problemas. 
"As maiores deficiências nas escolas do campo são: a falta de estrutura, materiais didáticos, as distâncias enfrentadas pelos professores e também pelos alunos, principalmente durante o inverno com as estradas esburacadas" (Professora $\mathrm{A}^{9}$ ).

A escola ainda possui uma cozinha, uma sala pequena que é utilizada como depósito para guardar merendas, materiais e livros, também existe um banheiro de alvenaria com duas repartições (masculino e feminino), mas está inapropriado para o uso.

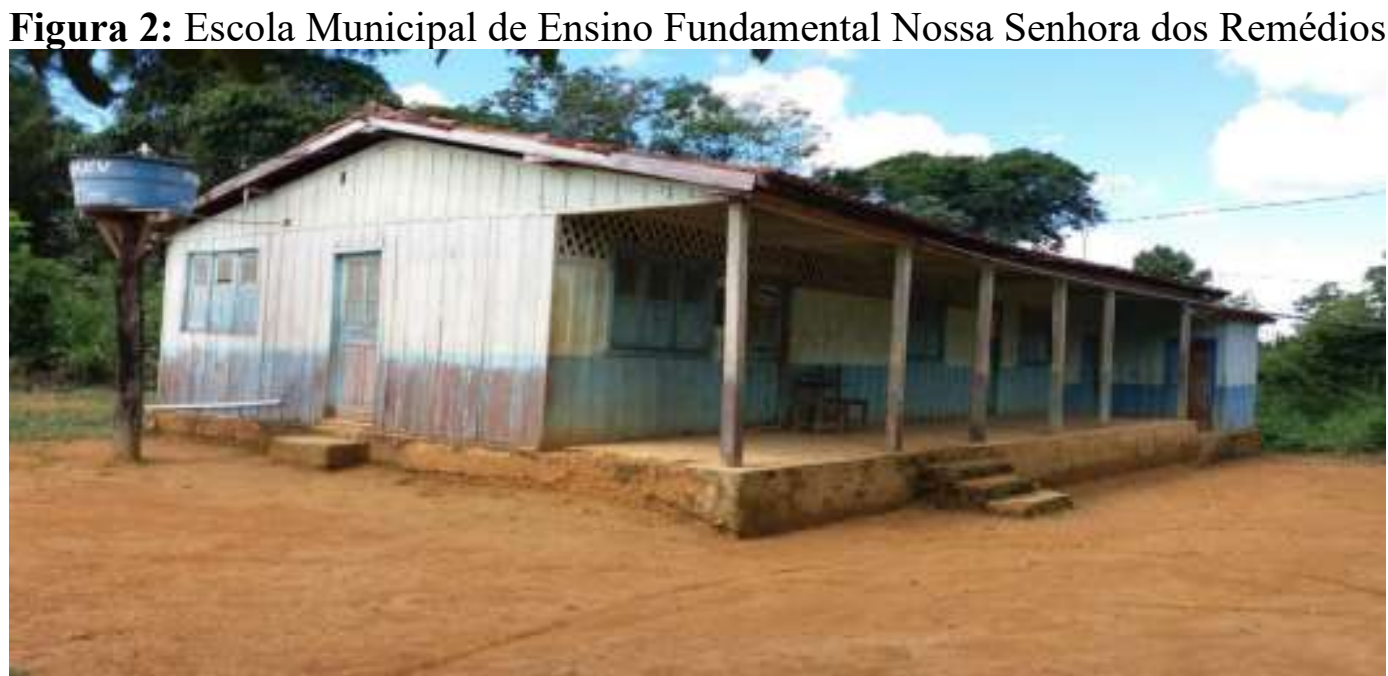

Fonte: Suziane P. de Freitas (2018).

Atualmente, calcula-se um número de 34 alunos do $1^{\circ}$ ao $5^{\circ}$ ano e do $6^{\circ}$ ao $9^{\circ}$ ano do Ensino Fundamental (anos iniciais e finais, respectivamente), todos divididos em turmas multianos (Turma 1: $1^{\circ}$ ao $5^{\circ}$ ano; Turma 2: $6^{\circ}$ e $7^{\circ}$ ano; e Turma 3: $8^{\circ}$ e $9^{\circ}$ ano), considerando o baixo número de alunos por ano atendidos pela escola. Esta forma de organização encontra justificativa no Art. 23 da LDB, quando assegura que:

A educação básica poderá organizar-se em séries anuais, períodos semestrais, ciclos, alternância regular de períodos de estudos, grupos não-seriados, com base na idade, na competência e em outros critérios, ou por forma diversa de organização, sempre que o interesse do processo de aprendizagem assim o recomendar (BRASIL, 1996, s/p, arquivo digital).

Os anos finais do Ensino Fundamental são ofertados para comunidades rurais de Pacajá por meio do SOME e isso não é diferente na E. M. E. F. N ${ }^{\mathrm{a}}$. Sra . dos Remédios, porém ocorre em turmas multianos. O SOME estadual serviu como "modelo" para implementar o SOME municipal. No entanto, ao contrário da oferta do sistema estadual, no caso específico do município, prevalecem as turmas multianos nos anos finais do Ensino Fundamental.

O Sistema de Organização Modular de Ensino - SOME, vem se ampliando significativamente no Estado do Pará e atende principalmente, o jovem-adulto em

\footnotetext{
${ }^{9}$ Os participantes do estudo serão identificados por letras de modo a manter o anonimato.
} 
busca de conclusão da Educação Básica, que não deseja sair de sua localidade ou não dispõe de recursos para tal situação. Pensado inicialmente como uma política "transitória", permanece para muitas localidades interioranas [...]. Trata-se de um projeto estadual, com professores vinculados ao Estado, que se operacionaliza, em muitos casos, na escola municipal, ocasionando orientações de ambas as redes para a gestão e organização do Sistema. O SOME insere-se no meio campesino, com o deslocamento dos professores para as localidades interioranas, objetivando trabalhar com e para os sujeitos do campo, propondo que o jovem estude e permaneça em sua comunidade (BRAYNER; TÁVORA, 2015, p. 38228)

De acordo com Brayner e Távora (2015), está explícito na Constituição Paraense, no Art. 281, IV, a necessidade de o plano estadual de educação conter, entre outras, medidas destinadas ao estabelecimento de modelos de ensino rural que considerem a realidade estadual específica. Deste modo, o SOME, “[...] propõe efetivar um processo educativo voltado à realidade dos cidadãos do campo e toma por base a premissa de que: a organização do trabalho pedagógico pauta-se nos estudos, pesquisas, debates, conflitos, etc." (BRAYNER; TÁVORA, 2015, p. 38231). Embora haja conflitos na implementação do programa e sua ligação com as várias dimensões da realidade campesina, fica explícita a tentativa de fomentar um projeto de escola do campo com objetivos pautados no diálogo, permanência e valorização dos contextos socioculturais e econômicos que perpassam a realidade dos moradores do campo.

No caso do SOME de Pacajá, assim como no estadual, as disciplinas são ofertadas por meio de módulos. Ao todo o ano letivo é dividido em nove módulos, cada um com duração de vinte e quatro dias letivos, com carga horária diária de 4h, visando cumprir os 200 dias letivos estabelecidos na LDB. No entanto, apenas duas professoras trabalham em cada Polo ${ }^{10}$ durante todo o ano, ou seja, essas duas professoras assumem um bloco de disciplinas cada uma $^{11}$. Após finalizar suas disciplinas numa dada escola elas seguem para outra comunidade do Polo para iniciar o mesmo bloco de disciplinas. Mesmo com graduações, não trabalham ou pouco atuam em suas áreas de formação específica: A Professora "A", formada em ciências sociais, atua nas disciplinas de língua portuguesa, ciências, Educação Física, artes e ensino religioso, enquanto a professora "B", licenciada em matemática, ministra matemática, história, geografia e inglês, organização recorrente nesta região, conforme

\footnotetext{
${ }^{10}$ É uma organização pedagógica e administrativa de um grupo de escolas circunvizinhas, onde os professores lotados no mesmo circulam nessas escolas, conforme os dias destinados à cada módulo.

${ }^{11}$ Ambas as professoras são participantes deste estudo. Elas residem na Vicinal Ladeira da Velha e atuam em duas escolas, com quase 10 anos de experiência cada uma, atuando no SOME nas escolas E.M.E.F. Na $S^{a}$ dos Remédios, localizada na ladeira da Velha e E.M.E.F Jesus Maria José, situada na comunidade São Vicente, no km-08, Pacajá-PA.
} 
apontam Tenório et al (2019) e Santos et al (2020) na contramão daquilo que preconiza o Art. 62 da LDB (BRASIL, 1996).

Sobre o sistema de trabalho adotado pela escola, a Professora "A" nos informou que a Secretária de Educação de Pacajá trabalha a educação nas áreas rurais com o SOME, elaborado em 2002 para atender a demanda de alunos que residem no campo, mais especificamente nas vicinais localizadas ao longo da Transamazônica, dentro do perímetro do Município de Pacajá. Devido à grande necessidade dos educandos que residem em áreas distantes e de difícil acesso, foi criado esse sistema conhecido por Polo que é a transição dos professores em escolas diferentes.

Considerando as especificidades desencadeadas pela forma de oferta dos anos finais do Ensino Fundamental em formato multino, as professoras interlocutoras da pesquisa precisam construir estratégias para conseguir desenvolver suas práticas docentes, a partir da realidade das escolas que atuam.

\section{A ESCOLA Nª $\mathrm{S}^{\mathrm{a}}$. DOS REMÉDIOS E AS PRÁTICAS DOCENTES NA TURMA MULTIANO}

Ao pensarmos os envolvidos no processo educativo em uma escola, podemos dizer, em última análise, que a qualidade, a efetividade e os impactos sobre os processos de ensino e de aprendizagem, estão ancorados, em grande medida, não só da seleção de conteúdo, planejamento, organização e sistematização didática do trabalho, mas na relação de proximidade e empatia construída entre professores e alunos, tarefa inicialmente colocada para o corpo docente na atividade escolar.

Sobre essa prática, Gadotti (2000, p. 9) afirma que:

O educador é um medidor do conhecimento, diante do aluno que é o sujeito da sua própria formação. Ele media no processo de construção de conhecimento, também precisa ser curioso e despertar a curiosidade, buscar sentido para o que faz e apontar novos sentido para o que fazer dos alunos.

Os conhecimentos das particularidades em que as escolas do campo estão instaladas se apresentam como instrumentos para um planejamento a curto, médio e longo prazo, que norteará ações previamente estabelecidas para atenderem as expectativas dos estudantes, dos professores e da própria comunidade. No entanto, em muitos casos, a Educação do Campo acaba não sendo contextualizada, e os professores se limitam ao uso de livros didáticos e não notam as dimensões e os desdobramentos do conteúdo em suas inserções sociais, culturais, políticas e econômicas nos modos de vida rural.

Ao pensarmos uma Educação do Campo para as classes multiano, comum às escolas do campo, compreendemos a lacuna deixada pelo Estado no enfrentamento das 
desigualdades e da invisibilidade dos povos que ali habitam. Santos e Moura (2010, p. 37) nos dizem que

Basta dizer que a única política pública implementada pelo Estado brasileiro para as classes multisseriadas, em nível nacional, é o Projeto Escola Ativa, desenvolvido a partir do ano de 1997, mas que se configura como uma ação isolada e se alicerça numa concepção política e pedagógica que não tem resistido às inúmeras críticas que lhe tem sido direcionada.

Assim, percebemos a oferta de uma educação mínima, que adota o modelo educacional que não supre necessariamente as carências, ainda que se leve em consideração a menor densidade populacional nas áreas rurais. Ao pesquisarmos a EMEF $\mathrm{N}^{\mathrm{a}}$. $\mathrm{S}^{\mathrm{a}}$. dos Remédios não conseguimos deixar de pensar nas indagações levantadas por Hage (2010, p. 348), quando destaca que essas lacunas se acentuam nas escolas multisseriadas:

Como pensar a educação e a escola do campo de nosso próprio lugar? Que currículo e propostas educativas apresentar que tenham a nossa cara, o nosso jeito de ser, de sentir, de agir e de viver amazônico? Como ressignificar o currículo da escola do campo de forma que articule a Amazônia à realidade nacional e internacional contemporânea e rompa com a precarização das escolas do campo, expressa em grande medida através das escolas multisseriadas?

As escolas do campo que adotaram regimes de organização pedagógica com turmas multiano enfrentam diversos problemas. Os dados encontrados na EMEF. $\mathrm{N}^{\mathrm{a}} \mathrm{S}^{\mathrm{a}} \operatorname{dos}$ Remédios aponta uma realidade similar: Segundo relatos dos professores, o trabalho docente é configurado pela sobrecarga de atividades e aflições relacionadas à organização do trabalho pedagógico, dada a dificuldade em lidar com diferentes idades no mesmo ambiente de aprendizagem, potencialidades múltiplas e ritmos de aprendizagem díspares. Em entrevista, a professora " $\mathrm{A}$ ” respondeu:

"[...] a maior dificuldade em trabalhar o currículo é a classe multiano, por ser várias séries e faixa etária diferente, e o desenvolvimento diferenciado de cada aluno, a estratégia que eu uso é a elaboração de sequência didática que facilita muito meu trabalho. Uso a mesma sequência para as duas séries, mudando somente o grau de dificuldade" (Grifos nossos).

A fala da professora nos aponta exatamente para o que Hage (2011, p. 101) sinaliza: "O trabalho com muitas séries ao mesmo tempo e com faixa etária, interesse e nível de aprendizagem muito variados dos estudantes impõe dificuldades aos professores para realizar o planejamento curricular nas escolas ou turmas multisseriadas". No entanto, a partir do relato da professora, percebemos que há iniciativas metodológicas utilizadas dentro desse contexto, como a padronização da sequência didática com diferentes graus de dificuldades, o que pode ser adequado e facilitador na organização do trabalho pedagógico. 
Ainda, os professores relatam a sobreposição de funções e responsabilidades, fato comum em várias escolas da região, como a confecção e distribuição da merenda, limpeza da sala de aula e espaços comuns da escola, angariamento de valores para despesas com materiais didáticos, dentre outras (HAGE, 2011; SANTOS et al, 2020).

Segundo Mouros e Santos (2012, p. 71):

O fenômeno das classes multisseriadas ou unidocentes, caracterizadas pela junção de alunos de diferentes níveis de aprendizagem (normalmente agrupadas em "séries") em uma mesma classe, geralmente submetida à responsabilidade de um único professor, tem sido uma realidade muito comum dos espaços rurais brasileiros, notadamente nas regiões Nordeste e Norte.

A professora "A" nos relatou sua sensação de que o "trabalho do professor da escola do campo é pouco valorizado", ao apontar a demanda de seu trabalho, que exige organização e planejamento, escolha dos conteúdos, realização de avaliações e proposição de metodologias e exercícios específicos para cada turma, o que, segundo ela, é muito difícil.

O município de Pacajá trabalha com o mesmo conteúdo programático que atende tanto a área urbana quanto rural. Pelo que foi relatado pelas docentes, não há um currículo flexível ou dialogado com os professores, pois suas diretrizes já vêm "praticamente pronto" (Professora “B) da Secretaria Municipal de Educação de Pacajá, numa configuração verticalizada, com pouca ou nenhuma participação dos professores e dos atores que compõem a pluralidade da comunidade escolar.

É no currículo que se sistematizam os esforços pedagógicos na escola, é o espaço central da atuação pedagógica para os docentes. O papel do educador se torna fundamental no processo de implementação curricular. Destacando os conteúdos a serem ensinados e aprendidos, os planos pedagógicos elaborados pelos professores, as experiências de aprendizagem escolar vividas pelos estudantes e principalmente os objetivos a serem alcançados no final da aplicação de cada conteúdo e os seus procedimentos aplicados nos diferentes graus de escolarização.

A professora "B" afirma que:

\footnotetext{
"Acredito que não há um currículo para turmas multiano, porque nós não temos acesso a currículo, o que temos é o planejamento anual na qual vem elaborado pela secretaria de educação e nós só reformulamos, adicionando ou retirando alguns conteúdos".
}

Se compreendermos o currículo como um conjunto de saberes, a "carreira" do estudante, a organização dos conteúdos e aquilo que se deve aprender e superar (SACRISTÁN, 2013), percebemos que a fala da professora é extremada ao afirmar "não há 
um currículo", mas demonstra lacunas no planejamento integrado, permanente e coletivo, que tanto se almeja em uma escola do campo.

Os professores sinalizam dificuldades na busca de alcançar as competências e habilidades que preconizam os Parâmetros Curriculares Nacionais (PCN's) ${ }^{12}$ dos anos finais do Ensino Fundamental. O documento apresenta possibilidades teóricas, metodológicas e curriculares que podem ser utilizadas pelo professor para o planejamento de suas aulas e implementação de atividades propostas aos alunos. Com atraso no recebimento de material e certa dependência do livro didático, os professores apontam as dificuldades em desenvolver um planejamento.

Além também da dificuldade em desenvolver um bom planejamento, porque quando recebemos os livros didáticos e a grade curricular já está terminando o ano letivo, e ai como é que vamos planejar uma boa aula se não temos suporte de apoio da secretaria de educação (Professora “B”).

Trabalho os conteúdos de acordo com o planejamento que é feito anualmente, e o suporte do livro didático, para as séries iniciais tem os livros especificos para Educação do Campo chamado Girassol e tem também o Campo Aberto, além de procurar ajuda na internet para melhorar os conteúdos didáticos no $8^{\circ}$ e $9^{a}$ ano. (Professora "A").

As professoras reconhecem que o ensino não é diferente do ensino da cidade, e que na escola do campo tem características particulares e para tanto deveria ter uma forma diferenciada que contemplasse essas particularidades, como metodologia e currículo entre outros diferentes das escolas urbanas.

Como já apontamos, as classes multianos trazem muitas dificuldades para a atividade docente como trabalhar em uma sala contemplando todos os alunos, independentemente do nível de conhecimento de cada um. Além disso, há dificuldades em realizar atendimentos individuais e planejamentos personalizados durante as aulas, que envolvem estudantes de dois ou mais anos numa mesma turma.

De acordo com o Art. 28 da LDB 9.394/96, os sistemas de ensino deverão desenvolver adaptações necessárias para as populações das áreas do campo, para que atendam as peculiaridades destas populações e de suas regiões:

I - Conteúdos curriculares e metodologias apropriadas às reais necessidades e interesses dos alunos da zona rural; II - organização escolar própria, incluindo adequação do calendário escolar às fases do ciclo agrícola e às condições climáticas; III - adequação à natureza do trabalho na zona rural. (BRASIL, 1996, p. 10).

\footnotetext{
${ }^{12}$ No período de desenvolvimento da pesquisa estava em discussão a implementação da Base Nacional Comum Curricular (BNCC)
} 
Para os professores, quando comparam a organização do trabalho pedagógico em turmas regulares com turmas multianos, sob o regime do SOME, identifica-se maiores dificuldades no alcance da interdisciplinaridade, tão almejada pela SEMED do município de Pacajá. As atividades se resumem a trabalhos com os alunos, aulas expositivas e dialogadas, simulações, debates, seminários, jogos, desenvolvimento de projetos, trabalhos em grupo, aulas experimentais e pesquisas na internet, livros, revistas e jornais, mesmo com dificuldades e falta de suporte técnico.

Sobre as classes multianos, foi apontado o apoio da comunidade em torno da escolha do modelo adotado, visto que muitas escolas do campo estão sendo fechadas pelas prefeituras com o argumento do reduzido número de matrículas, o que, evidentemente, agrava o acesso à escola e, consequentemente, o direito à Educação, conforme aponta Hage (2010, p. 353):

\begin{abstract}
Os sujeitos em geral consideram as escolas multisseriadas como "um mal necessário", identificando pontos positivos e negativos em relação a sua existência, e isso interfere diretamente na ação educativa por eles vivenciada. Os aspectos positivos ressaltados nos depoimentos referem-se ao fato dos estudantes terem acesso à escolarização no próprio local em que vivem e serem estimulados a apoiarem-se mutuamente na aprendizagem, a partir da convivência mais próxima estabelecida entre estudantes de várias séries. As posições que expressam uma concepção de insatisfação com relação à multissérie, por sua vez, consideram a existência dessas escolas um "problema" que prejudica o processo de aprendizagem. Constantemente, o ensino que ocorre nas escolas multisseriadas é comparado ao que ocorre em turmas seriadas, manifestando-se a expectativa de que essas escolas se transformem em seriadas, como alternativa para que o sucesso na aprendizagem se efetive.
\end{abstract}

Desta forma, a pesquisa corrobora com o autor no apontamento dos aspectos positivos e negativos do formato multiano e acrescentamos que, mesmo com todas as problemáticas levantadas, são esperançosas as perspectivas do trabalho dos docentes e que a busca na superação dos problemas continua, diariamente por eles e pelos estudantes. Foi apontado ainda pelos professores que a coordenação pedagógica da escola vem buscando, através de um processo de discussão, estabelecer parâmetros para uma prática pedagógica que alcance a identidade no campo e as relações de cumplicidade com a comunidade.

\title{
CONSIDERAÇÕES FINAIS
}

A presente pesquisa nos mostra alguns desafios que os docentes enfrentam em seu trabalho pedagógico, ao trabalhar com os professores da Escola Municipal de Ensino Fundamental Nossa Senhora dos Remédios e seus relatos sobre a realidade em que vivem. Ao buscar um percurso teórico sobre a história da Educação do Campo frente ao rompimento 
com a educação Rural, pensamos no que falta para efetivar uma educação personalizada aos sujeitos do campo, que respeite as identidades, territórios e a cultura dos povos que ali habitam, bem como os documentos normativos da Educação formal.

Ao considerar as dificuldades da prática pedagógica verificamos as lacunas que temos para balizar as deficiências educacionais desta parcela da população, que tem no ensino multiano a única maneira de acessar os saberes universais e o direito garantido pela constituição brasileira. Por se tratar de uma turma multiano, nota-se que o professor se divide na explicação dos conteúdos para atender outros alunos que o demandam, resultando em um baixo rendimento da aprendizagem. Por mais que se constate um querer para melhorar a Educação em classes multiano, não é fácil, pois é necessário capacitação continuada e permanente para a realidade específica local e maior apoio por parte da SEMES, que se restringe a transmitir os conteúdos programáticos previamente escolhidos, cabendo a comunidade escolar apenas "adaptar" e implementar a sua maneira. Carecemos de um olhar do poder público aos educadores e formadores das Escolas do Campo.

Precisamos de um acompanhamento real, de Políticas públicas educacionais e recursos que cheguem e permaneçam em nossas escolas. Um olhar digno e reconhecimento dos sujeitos que permitem a existência de tais escolas no Brasil.

De acordo com a pesquisa, são inúmeros os problemas encontrados nas Escolas do Campo, que vão desde a sobreposição de funções e responsabilidade docente à ausência de materiais didáticos adequados, falta de debates e reformulação do currículo, carência de acompanhamento pedagógico formativo e permanente, dentre outros. Embora tais questões não sejam exclusivas do ambiente das escolas do Campo situadas nas vicinais que cruzam a rodovia transamazônica, demonstrar tal realidade é fundamental no enfrentamento dos problemas e na veiculação das informações de sucateamento e abandono em que vivem tais escolas, desta forma, buscamos reduzir a distância para uma Educação do Campo de qualidade e verdadeiramente emancipadora.

\section{REFERÊNCIAS}

ARROYO, Miguel Gonzalez; CALDART, Roseli Salete; MOLINA, Mônica Castagna (Orgs.). Por uma educação do campo. Petrópolis: Vozes, 2004.

BRASIL, Decreto $\mathbf{n}^{\mathbf{0}} \mathbf{7 . 3 5 2}$, de 4 de novembro de 2010. Dispõe sobre a política de educação do campo e o Programa Nacional de Educação na Reforma Agrária - PRONERA. Diário Oficial [da União], Poder Executivo, Brasília, DF, 2010. Disponível em: http://www.planalto.gov.br/ccivil_03/_ato2007-2010/2010/decreto/d7352.htm. Acesso em: 20 out. 2020. 
BRASIL. Ministério da Educação - Diretrizes operacionais para a educação básica nas escolas do campo. Brasília, DF, 2002.

BRASIL. Ministério da Educação. Conselho Nacional de Educação. Câmara de Educação Básica. Resolução no 2, de 28 de abril de 2008. Estabelecem diretrizes complementares, normas e princípios para o desenvolvimento de políticas públicas de atendimento da Educação Básica do Campo. Disponível em http://www.mec.gov.br Acesso em: 15 de março de. 2021.

BRASIL. Ministério da Educação. Lei das diretrizes e bases da educação nacional $\mathbf{n}^{0}$ 9394 de 20 de dez de 1996. Disponível em: $<$ http://www.presidencia.gov.br/ccivil_03/Leis/L9394.htm>. Acesso em: 20 de março de 2021.

BRAYNER, Conceição de Nazaré de Morais; TÁVORA, Maria Josefa de Souza. Democratização do acesso ao ensino médio para população do Campo no Pará: Uma análise a partir do sistema modular de ensino. In.: XII Congresso Nacional de Educação - EDUCERE, 2015. Anais do EDUCERE. Paraná: Universidade Católica do Paraná PUCPR, 2015. p. 38227 a 38240.

BRITO, Tatiane Novais. Educação do Campo: Caminhos possíveis para construção de práticas educativas significativas. Revista Diálogos e Perspectivas em Educação. Marabá-PA, v.2, n. 1, p.90-105, jan.-jun.2020.

CALDART, R. S.. Sobre Educação do Campo. In: SANTOS, C. A. F, MANÇANO, B. (Orgs.). Educação do Campo: Campo - políticas públicas - educação. Brasília: Incra MDA, 2008.

CAlDART, R. S.; PEREIRA, I. B.; ALENTEJANO, P.; FRIGOTTO, G (Orgs.). Dicionário da Educação do Campo. Rio de Janeiro, São Paulo: Escola Politécnica de Saúde Joaquim Venâncio, Expressão Popular, 2012.

CALDART, Roseli Salete. A escola do campo em movimento. In.: ARROYO, Miguel Gonzalez; CALDART, Roseli Salete; MOLINA, Mônica Castagna. (Orgs.). Por uma Educação do Campo. 5. ed. Petrópolis - RJ: Vozes, 2011.

FREIRE, Paulo. A Importância do Ato de Ler: Em três artigos que se completam. 32 ed. São Paulo: Cortez, 1996.

FREIRE, Paulo. Pedagogia do oprimido. 34. ed. São Paulo: Paz e Terra, 2002.

GADOTTI, M. Perspectivas atuais da educação. Porto Alegre, Ed. Artes Médicas, 2000.

HAGE, S. A. M; BARROS, O. F.. Currículo e Educação do Campo na Amazônia: Referências para o debate sobre a multisseriação na escola do campo. Espaço do Currículo. v.3. n.1, pp.348-362, Março a Setembro de 2010.

HAGE, S. M.. Por uma escola do campo de qualidade social: transgredindo o paradigma (multi)seriado de ensino. Em aberto, Brasília, v. 24, n. 85, p. 97-113, 2011.

LEITE, Francisco Tarciso. Metodologia Científica: Métodos e técnicas de pesquisa, monografias, dissertações, teses e livros. Aparecida - SP: Ideias e Letras, 2008.

LEITE, S. C.. Escola rural: urbanização e políticas educacionais. São Paulo: Cortez, 1999.

LIBÂNEO, J. C.. O dualismo perverso da escola pública brasileira: escola do conhecimento para os ricos, escola do acolhimento social para os pobres. Educação e Pesquisa, São Paulo, v. 38, n. 1, p. 13-28, 2012. Disponível em: http://www.scielo.br/pdf/ep/v38n1/aop323.pdf. Acesso em: 11 de Fevereiro de 2021. 
LIMA, Elmo de Souza; MELO, Keylla Rejane Almeida (Orgs.). Educação do Campo: Reflexões políticas e teórico-metodológicas. Teresina: EDUFPI, 2016.

MAXIMIANO, A. C. A. Teoria geral da administração: da revolução urbana à revolução digital. 5. ed. São Paulo: Atlas, 2005.

PANTOJA, W. W. R. Transamazônica: Geocartografia da (in)existência entre lugares. Tese de Doutorado apresentada ao Programa de Pós-Graduação em Geografia do Instituto de Ciências Humanas da Universidade de Brasília, como requisito para obtenção do título de Doutor em Geografia. 2010.

PINHEIRO, M. S. D.. A concepção de educação do campo no cenário das políticas públicas da sociedade brasileira. Cadernos ANPAE. Rio Grande do Sul: UFRGS, 2007.Acesso em: 07 de Março de 2018.

SACRISTÁN, J. G.. Saberes e Incertezas sobre o currículo. Porto Alegre: Penso, 2013.

SANTOS, F. J. S.; MOURA, T. V. Políticas educacionais, modernização pedagógica e racionalização do trabalho docente: problematizando as representações negativas sobre as classes multisseriadas. In: ANTUNES-ROCHA, M. I.; HAGE, S. M. (orgs.). Escola de direito: reinventando a escola multisseriada. Belo Horizonte: Autêntica, 2010. (Coleção Caminhos da Educação do Campo; v. 2), pp. 35-48.

SANTOS, I. V. F.; SILVA, M. R.; FORMIGOSA, M. M.; GOMES, F. B. R. Desafios da Educação do Campo: o ensino de Ciências e a realidade da comunidade Santo Antônio. Research, Society and Development, [S. 1.], v. 9, n. 1, p. e187911790, 2020

SCHEIN, E. Organizational culture and leadership. San Francisco: Jossey-Bass, 1985.

TENÓRIO, W.; FORMIGOSA, M.; ROCHA, C. G. S.; SANTANA, R. A formação e atuação docente na disciplina de ciências em escolas do campo na Amazônia Paraense. Revista Insignare Scientia - RIS, v. 2, n. 4, p. 158-179, 19 dez. 2019.

VILHENA JUNIOR, W. M.; MOURÃO, A. R. B. Políticas Públicas e os Movimentos Sociais por uma Educação do Campo. In.: GHEDIN, E. (Org). Educação do Campo: Epistemologias e Práticas. São Paulo, Cortez, 2012.

\section{Autores}

Doutor em Estudos de Cultura Contemporânea pela Universidade Federal de Mz (PPGECCO/UFMT). Mestre em Educação também pela Universidade Federal de Mato Grosso (PPGE/UFMT) na Linha de pesquisa: Movimentos sociais, Política e Educação popular; Licenciado em Ciências Biológicas pela Universidade do Estado de Mato Grosso e em Pedagogia pela Faculdade de Ciências Humanas de Vitória. Criador e Coordenador (Líder) do Grupo de Estudos sobre Natureza, Cultura e Etnosaberes da Amazônia (GENCEA) - UFPA/CNPq. Professor Adjunto da Universidade Federal do Pará - UFPA Tem Experiência na área da Educação/Educação do Campo, com ênfase no Ensino de Ciências, Educação Ambiental e Etnosaberes.

Universidade Federal do Pará (UFPA). Doutor em Estudos de Cultura Contemporânea (UFMT). Professor Adjunto da Faculdade de Etnodiversidade - UFPA- Campus Universitário de Altamira Altamira - PA, Brasil.

ronaldobio@ufpa.br https://orcid.org/0000-0002-8006-1289

Suziane Pereira de Freitas suzianepereira97@gmail.com https://orcid.org/0000-0002-0775-9824 Universidade Federal do Pará (UFPA). Licenciada em Educação do Campo (UFPA). Pacajá - PA, Brasil. 
Marcos Marques Formigosa

Doutorando em Ensino na Universidade do Vale do Taquari (Univates - RS). Mestre em Educação em Ciências e Matemáticas pela Universidade Federal do Pará (UFPA). Especialista em Extensão Rural, Sistemas Agrários e Ações de Desenvolvimento (UFPA). Licenciado Pleno em Matemática (UFPA). Professor Assistente II da Universidade Federal do Pará.Entre 2016-2019 foi coordenador do curso de Educação do Campo (curso avaliado com nota 5 pelo MEC). Membro da Sociedade Brasileira de Educação Matemática (SBEM); Membro da Rede Internacional de Etnomatemática;

Membro da Associação Brasileira de História Oral (ABHO); Líder do Grupo de Estudos e Pesquisas sobre Práticas Etnos do/no Xingu (GEPPEX). É pesquisador do Grupo de Estudos e Pesquisa sobre Memória, Formação Docente e Tecnologia (GEPEMe/UFPA); Coordenador do Fórum Regional de Educação do Campo da Transamazônica e Xingu. Tem experiência na área de

Matemática e Ciências, com ênfase em Educação Matemática e Ensino de Ciências, atuando principalmente nos seguintes temas: educação matemática; ensino de matemática; etnomatemática; alfabetização matemática; ensino de ciências; etnofísica; educação do campo; educação ribeirinha; formação de professores de ciências e matemática; políticas públicas para o campo; movimentos sociais; educação não-formal; extensão rural; ações de desenvolvimento.

Universidade Federal do Pará (UFPA) Doutor em Ensino (UNIVATES). Professor Adjunto da Faculdade de Etnodiversidade - UFPA - Campus Universitário de Altamira Altamira - PA, Brasil. mformigosa@ufpa.br https://orcid.org/0000-0001-6279-1459 